\title{
Molecular Dye-Sensitized Photocatalysis with Metal-Organic Framework and Metal Oxide Colloids for Fuel Production
}

\author{
Philip M. Stanley (1) and Julien Warnan*
}

check for updates

Citation: Stanley, P.M.; Warnan, J.

Molecular Dye-Sensitized

Photocatalysis with Metal-Organic Framework and Metal Oxide Colloids for Fuel Production. Energies 2021, 14, 4260. https://doi.org/10.3390/ en14144260

Academic Editor: Umberto Desideri

Received: 8 June 2021

Accepted: 9 July 2021

Published: 14 July 2021

Publisher's Note: MDPI stays neutral with regard to jurisdictional claims in published maps and institutional affiliations.

Copyright: (c) 2021 by the authors. Licensee MDPI, Basel, Switzerland. This article is an open access article distributed under the terms and conditions of the Creative Commons Attribution (CC BY) license (https:// creativecommons.org/licenses/by/ $4.0 /)$.
Chair of Inorganic and Metal-Organic Chemistry, Department of Chemistry, Technical University of Munich, 85748 Garching, Germany; philip.stanley@tum.de

* Correspondence: julien.warnan@tum.de; Tel.: +49-(0)89-289-13147

\begin{abstract}
Colloidal dye-sensitized photocatalysis is a promising route toward efficient solar fuel production by merging properties of catalysis, support, light absorption, and electron mediation in one. Metalorganic frameworks (MOFs) are host materials with modular building principles allowing scaffold property tailoring. Herein, we combine these two fields and compare porous $\mathrm{Zr}$-based $\mathrm{MOFs} \mathrm{UiO}-66-\mathrm{NH}_{2}(\mathrm{Zr})$ and $\mathrm{UiO}-66(\mathrm{Zr})$ to monoclinic $\mathrm{ZrO}_{2}$ as model colloid hosts with co-immobilized molecular carbon dioxide reduction photocatalyst $f a c-\operatorname{ReBr}(\mathrm{CO})_{3}\left(4,4^{\prime}\right.$-dcbpy) (dcbpy = dicarboxy-2,2'-bipyridine) and photosensitizer $\mathrm{Ru}(\mathrm{bpy})_{2}\left(5,5^{\prime}\right.$-dcbpy $\mathrm{Cl}_{2}$ (bpy $=2,2^{\prime}$-bipyridine). These host-guest systems demonstrate selective $\mathrm{CO}_{2}$-to-CO reduction in acetonitrile in presence of an electron donor under visible light irradiation, with turnover numbers (TONs) increasing from $\mathrm{ZrO}_{2}$, to UiO-66, and to UiO-66-NH turn. This is attributed to MOF hosts facilitating electron hopping and enhanced $\mathrm{CO}_{2}$ uptake due to their innate porosity. Both of these phenomena are pronounced for UiO-66- $\mathrm{NH}_{2}(\mathrm{Zr})$, yielding TONs of 450 which are 2.5 times higher than under MOF-free homogeneous conditions, highlighting synergistic effects between supramolecular photosystem components in dye-sensitized MOFs.
\end{abstract}

Keywords: dye-sensitized; metal-organic frameworks; metal oxides; host-guest photosystems; molecular catalysis; fuel production; artificial photosystems

\section{Introduction}

Solar fuel production has emerged as a pertinent possibility on route to address growing energy challenges and shift fossil fuel dependency toward sustainable sources [1]. It aptly merges solar energy harvesting with subsequent energy conversion to form valueadding products [2]. At this cross-section, molecular coordination complexes can play a key role as discrete nature-mimicking photosystems combining light sensitizing and chemical reactivity [3]. Previous advances include molecular catalyst and dye engineering to improve catalytic parameters such as activity and selectivity on the one hand, as well as light harvesting and antenna effects on the other [4,5]. Additionally, immobilizing such species to host materials can yield beneficial sustained performance, with dye-sensitized photocatalysis (DSP) emerging as a selected approach with distinct advantages [6,7]. Specifically, this methodology bridges the fields of molecular (photo)catalysis and material chemistry by coupling a catalyst and a dye via co-anchoring onto a semiconductor particle-effectively employing the latter as a solid-state electron mediator and a scaffold [6]. While this working principle has been studied for several host particle compounds in colloidal DSP [8,9], applying metal-organic frameworks (MOFs) as the matrix component can provide similar benefits and is an area with burgeoning interest [10-13]. MOFs combine metal-based nodes with organic multitopic linkers to form porous coordination polymers, thus unlocking adjustable chemical properties, topologies, porosities, and molecular complex hosting capabilities [14]. Particularly regarding dye-sensitization possibilities, MOFs can substantially influence guest photophysics through approaches such as confinement effects as well as scaffold-directed photochromicity [15]. However, their organic/inorganic building principle can result in limited stability or conductivity [16]. This presents the question how 
dye-sensitized MOFs (DSMs) directly compare to their commonly used metal oxide-based particle counterparts in colloidal solar fuel production.

We devised a conceptual side-by-side model comparison of $\mathrm{CO}_{2}$ reducing DSP and DSM systems based on $\mathrm{ZrO}_{2}$ nanoparticles alongside the UiO-66( $\left.\mathrm{Zr}\right)$ MOF composed of $\mathrm{Zr}_{6} \mathrm{O}_{4}(\mathrm{OH})_{4}$ nodes, simulating the oxide support (Figure 1a,b) [17].

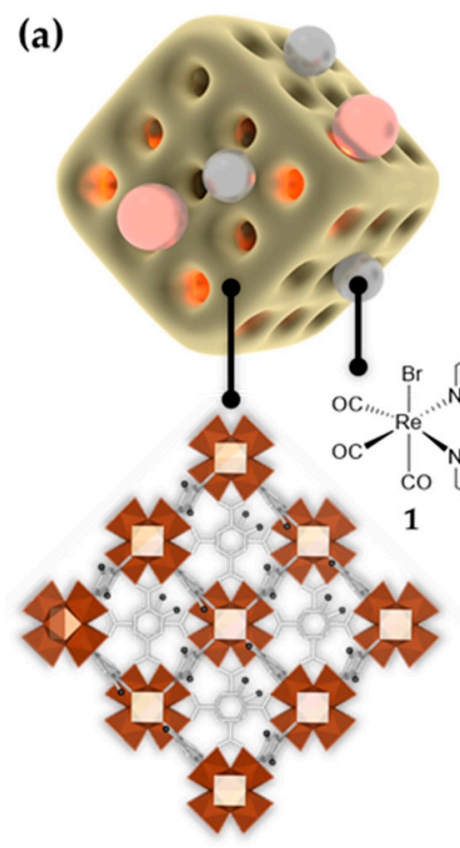

UiO-66- $\mathrm{NH}_{2}(\mathrm{Zr})$

(b)

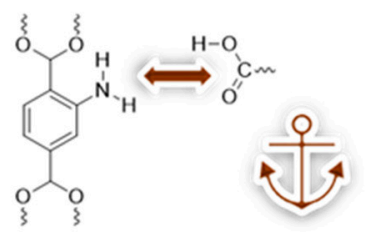

Amine Groups (66- $\left.\mathrm{NH}_{2}\right)$
MOF Nodes $\left(66-\mathrm{NH}_{2}, 66\right)$

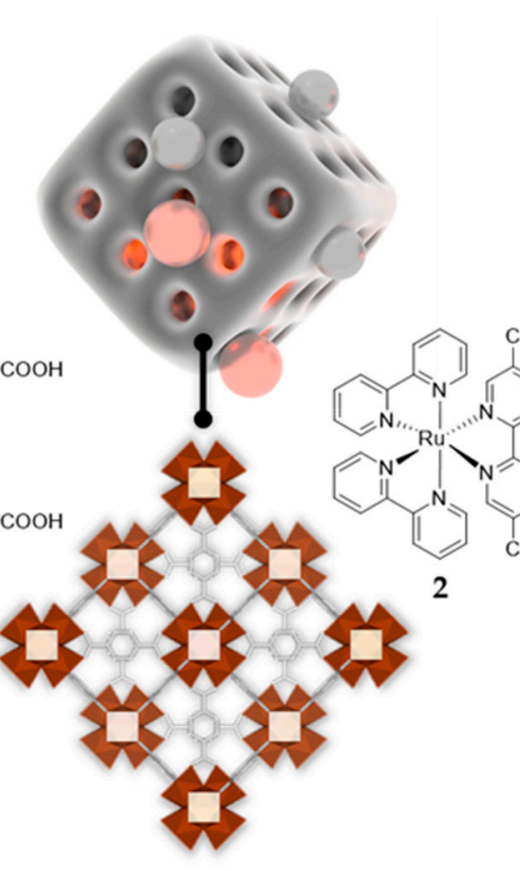

UiO-66(Zr)

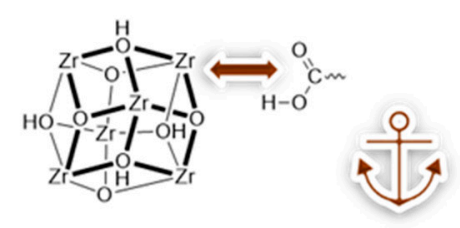

Crystal Surface $\left(\mathrm{ZrO}_{2}\right)$

Figure 1. Schematic overview of the studied hosts and molecular complexes. (a) Representation of the porous MOF hosts $\mathrm{UiO}-66-\mathrm{NH}_{2}(\mathrm{Zr})\left(66-\mathrm{NH}_{2}\right)$ and $\mathrm{UiO}-66(\mathrm{Zr})(66)$, as well as monoclinic $\mathrm{ZrO}_{2}$ nanoparticles. Chemical structures of the molecular photocatalyst fac- $\operatorname{ReBr}(\mathrm{CO})_{3}\left(4,4^{\prime}\right.$-dcbpy) (1) and the $\left[\operatorname{Ru}(\text { bpy })_{2}\left(5,5^{\prime}\right.\right.$-dcbpy $\left.)\right] \mathrm{Cl}_{2}$ photosensitizer (2). (b) Anchoring interactions between the molecular species 1 and 2 to $66,66-\mathrm{NH}_{2}$ and $\mathrm{ZrO}_{2}$, respectively.

UiO-66 is well-studied due to its versatility and chemical stability [18]. Additionally, a few reports showed UiO-66(Zr)'s applicability in DSM using Pt nanoparticles for $\mathrm{H}_{2}$ evolution $[19,20]$. Functional group implementation through linker variation offers further advantages [18]. For example, $\mathrm{UiO}-66-\mathrm{NH}_{2}(\mathrm{Zr})$, constructed from 2-aminoterephthalic acid linkers, allows improved gas and molecular guest adsorption capabilities, as well as shifts the optical absorption through amine group incorporation [10,21]. Due to its small pore apertures and diameters, molecular species are typically loaded onto the $\mathrm{MOFs}^{\prime}$ surface $[10,22] . \mathrm{ZrO}_{2}$ has also been previously applied as a support for DSP primarily enabling so-called "on particle" electronic communication between PS and catalyst due to the high energy level of the conduction band $[3,23]$.

We selected a molecular $\mathrm{CO}_{2}$ reduction catalyst (CRC) fac- $\operatorname{ReBr}(\mathrm{CO})_{3}\left(4,4^{\prime}\right.$-dcbpy) $(\mathrm{dcbpy}=$ dicarboxy-2,2'-bipyridine $)(\mathbf{1})$ and the photosensitizer $\left[\mathrm{Ru}(\mathrm{bpy})_{2}\left(5,5^{\prime}-\mathrm{dcbpy}\right)\right] \mathrm{Cl}_{2}$ (bpy $=2,2^{\prime}$-bipyridine) (2) as a benchmark photosystem (Figure 1a). These have been studied together under homogeneous conditions in the presence of a sacrificial electron donor (SED) $[10,24,25]$, as well as in DSP upon anchoring to semiconductor supports such 
as $\mathrm{TiO}_{2}, \mathrm{SiO}_{2}$, and $\mathrm{SrTiO}_{3}$, as well as to MOFs, often delivering moderate photoactivity with turnover numbers (TONs) in the range of 10-600 [10,11,26-29].

Ligands with carboxylic acid groups were chosen to enable outer surface anchoring to MOF nodes, free amines for UiO-66- $\mathrm{NH}_{2}(\mathrm{Zr})$, as well as to $\mathrm{ZrO}_{2}$ surface hydroxyl groups (Figure $1 b)[11,12,30]$. This approach has previously yielded stable host-guest colloidal assemblies, allowing for photoinduced electron transfers from the SED to the sensitizing units and subsequently to vicinal catalysts for $\mathrm{CO}_{2}$ reduction [10-13,30]. Herein, we report the synthesis, thorough characterization, and photocatalytic $\mathrm{CO}_{2}$ reduction performance of DSM UiO-66- $\mathrm{NH}_{2}(\mathrm{Zr})$ and UiO-66( $\left.\mathrm{Zr}\right)$, in direct comparison to DSP with their metal oxide counterpart $\mathrm{ZrO}_{2}$. This revealed key working principles and considerations for selecting suitable hosts in solar DSP and DSM.

\section{Materials and Methods}

A detailed overview on analysis methods, step-by-step synthesis routes, and characterization techniques is available to the reader in the Supplementary Material (SM). The most relevant material syntheses are described here.

\section{fac- $\operatorname{ReBr}(\mathrm{CO})_{3}\left(4,4^{\prime}-\mathrm{dcbpy}\right)(\mathbf{1})$}

The synthesis was conducted according to a modified literature procedure [25]. $\operatorname{ReBr}(\mathrm{CO})_{5}(0.30 \mathrm{~g}, 0.74 \mathrm{mmol}, 1.0$ eq.) was dissolved in ethylene glycol dimethyl ether $(20 \mathrm{~mL})$ in an argon atmosphere. 4,4'-dicarboxyl-2,2'-bipyridine $(0.18 \mathrm{~g}, 0.74 \mathrm{mmol}, 1.0 \mathrm{eq}$. was added to the solution and stirred at $90^{\circ} \mathrm{C}$ overnight. After cooling, the solvent was removed in vacuo and the residue was dissolved in minimal amounts of ethylene glycol dimethyl ether and added to hexane $(100 \mathrm{~mL})$ at $0{ }^{\circ} \mathrm{C}$. The solid was then isolated via centrifugation and dried to afford the product, matching literature characterizations [25].

${ }^{1} \mathrm{H}$ NMR $\left(400 \mathrm{MHz}, 300 \mathrm{~K}, \mathrm{CD}_{3} \mathrm{CN}\right): \delta(\mathrm{ppm})=9.20\left(\mathrm{~d},{ }^{3} \mathrm{~J}=5.7 \mathrm{~Hz}, 2 \mathrm{H}\right), 8.95(\mathrm{~s}, 2 \mathrm{H})$, $8.06\left(\mathrm{~d},{ }^{3} \mathrm{~J}=5.7 \mathrm{~Hz}, 2 \mathrm{H}\right)$; ATR-IR $\left(\operatorname{Re}(\mathrm{CO})_{3}\right)=1870,1915$ and $2021 \mathrm{~cm}^{-1}$

$\mathrm{Ru}(\mathrm{bpy})_{2}\left(5,5^{\prime}\right.$-dcbpy) $\mathrm{Cl}_{2} \cdot 6 \mathrm{H}_{2} \mathrm{O}$ (2)

The synthesis was performed following a literature known procedure [31]. 5,5'-dicarboxyl2,2'-bipyridine ( $0.064 \mathrm{~g}, 0.260 \mathrm{mmol}, 1.27$ eq.) and $\mathrm{Ru}(\mathrm{bpy}){ }_{2} \mathrm{Cl}_{2}(0.10 \mathrm{~g}, 0.21 \mathrm{mmol}, 1.00$ eq.) and were dissolved in ethanol/water $(15 \mathrm{~mL}, 1 / 1 \mathrm{v} / \mathrm{v})$ and refluxed for $25 \mathrm{~h}$ in an Ar atmosphere. After cooling, the solvent was removed in vacuo. The resulting powder was dissolved in water, filtered, and the filtrate was evaporated to give the crystalline product (0.120 $\mathrm{mg}, 0.143 \mathrm{mmol}, 70 \%$ yield), matching literature characterizations [31].

${ }^{1} \mathrm{H}$ NMR $\left(400 \mathrm{MHz}, 300 \mathrm{~K}, \mathrm{DMSO}-\mathrm{d}_{6}\right): \delta(\mathrm{ppm})=8.87(\mathrm{~m}, 4 \mathrm{H}), 8.80\left(\mathrm{~d},{ }^{3} \mathrm{~J}=8.3 \mathrm{~Hz}\right.$, $2 \mathrm{H}), 8.37\left(\mathrm{~d},{ }^{3} \mathrm{~J}=8.1 \mathrm{~Hz}, 2 \mathrm{H}\right), 8.19(\mathrm{~m}, 4 \mathrm{H}), 8.00(\mathrm{~s}, 2 \mathrm{H}), 7.79\left(\mathrm{~d},{ }^{3} \mathrm{~J}=5.6 \mathrm{~Hz}, 2 \mathrm{H}\right), 7.77(\mathrm{~d}$, $\left.{ }^{3} J=5.6 \mathrm{~Hz}, 2 \mathrm{H}\right), 7.58\left(\mathrm{t},{ }^{3} \mathrm{~J}=6.5 \mathrm{~Hz}, 2 \mathrm{H}\right), 7.53\left(\mathrm{t},{ }^{3} \mathrm{~J}=6.5 \mathrm{~Hz}, 2 \mathrm{H}\right)$

\section{UiO-66- $\mathrm{NH}_{2}(\mathrm{Zr})$}

The synthesis was modified from a literature procedure [32]. 2-aminoterephthalic acid (0.186 g, $1.03 \mathrm{mmol}, 1.00$ eq.) and $\mathrm{ZrCl}_{4}(0.240 \mathrm{~g}, 1.03 \mathrm{mmol}, 1.00$ eq.) were dissolved in anhydrous $\mathrm{N}, \mathrm{N}$-dimethylformamide (DMF, $60 \mathrm{~mL}$ ). To the mixture deionized water $(0.19 \mathrm{~mL})$ was added. The mixture was stirred at r.t. for $10 \mathrm{~min}$ and then transferred to a $100 \mathrm{~mL}$ Teflon liner before heating at $120^{\circ} \mathrm{C}$ for $24 \mathrm{~h}$ to yield a yellow solid. The latter was isolated by centrifugation, washed with DMF $(3 \times)$ and methanol $(3 \times)$, immersed in methanol for 2 days with solvent exchange $(2 \times)$, and dried at $80^{\circ} \mathrm{C}$ in vacuo to yield UiO-66- $\mathrm{NH}_{2}(\mathrm{Zr})(0.244 \mathrm{~g})$.

\section{$\mathrm{UiO}-66(\mathrm{Zr})$}

The synthesis was modified from a literature procedure [33]. $\mathrm{ZrCl}_{4}(0.100 \mathrm{~g}, 0.43 \mathrm{mmol})$ was dissolved in DMF $(25 \mathrm{~mL})$ in a Teflon autoclave by sonication. Then terephthalic acid $(71.3 \mathrm{mg}, 0.43 \mathrm{mmol})$ and distilled water $(0.033 \mathrm{~mL}, 1.71 \mathrm{mmol})$ were added to the solution. The solution was heated for $24 \mathrm{~h}$ at $120^{\circ} \mathrm{C}$. After cooling, the MOF nanoparticles were isolated by centrifugation washed with DMF $(3 \times)$ and methanol $(3 \times)$, immersed in methanol for 2 days with solvent exchange $(2 \times)$, and dried at $80^{\circ} \mathrm{C}$ in vacuo to yield $\mathrm{UiO}-66(\mathrm{Zr})(0.112 \mathrm{~g})$. 
$\mathrm{ZrO}_{2}$

Zirconium oxide nanoparticles (99.9\%, $50 \mathrm{~nm}$, monoclinic, nanopowder, $100 \mathrm{~g}$ ) were purchased from GetNanoMaterials ${ }^{\circledR}$.

Molecular Complex Immobilization

In a typical experiment, a $0.09 \mathrm{mM}$ solution of $\mathbf{1}$ in acetonitrile (MeCN) and a $0.05 \mathrm{mM}$ solution of 2 in MeCN (quantities for both varied according to the desired ratio, see SI, Table S1) were added simultaneously to the respective pristine host powder $(10.0 \mathrm{mg})$. The supernatant was removed after $24 \mathrm{~h}$, and the resulting powder was washed with pure $\operatorname{MeCN}(3 \times 20 \mathrm{~mL})$. Then the powder was dried at $80{ }^{\circ} \mathrm{C}$ overnight.

\section{Results}

\subsection{Catalyst, Dye, and Host Characterization}

The CRC 1 showed two characteristic UV-Vis absorption bands in MeCN, namely a $\pi-\pi^{*}$ transition at $310 \mathrm{~nm}$ as well as a metal to ligand charge transfer (MLCT) transition at $415 \mathrm{~nm}$ (molar absorption coefficient $\varepsilon=\sim 1100 \mathrm{dm}^{3} \mathrm{~mol}^{-1} \mathrm{~cm}^{-1}$, Figure S1) with a reduction potential $\mathrm{E}\left(\mathbf{1} / \mathbf{1}^{-}\right)$of $-0.94 \mathrm{~V}$ vs saturated calomel electrode $\left(\mathrm{V}_{\mathrm{SCE}}\right)$ [24,34]. The molecular dye 2 displayed two predominant UV-Vis bands in MeCN, a $\pi-\pi^{*}$ transition at $288 \mathrm{~nm}$ and also a ${ }^{1}$ MLCT at $450 \mathrm{~nm}\left(\varepsilon=\sim 15000 \mathrm{dm}^{3} \mathrm{~mol}^{-1} \mathrm{~cm}^{-1}\right)$, allowing for strong visible light absorption (Figure S1). The latter yields the triplet excited state ${ }^{3} \mathrm{Ru}(\mathrm{bpy})_{2}\left(5,5^{\prime}-\mathrm{dcbpy}\right)^{*}$ with an excited state reduction potential $\mathrm{E}\left({ }^{3} \mathbf{2}^{*} / \mathbf{2}^{-}\right)$of $1.07 \mathrm{VSCE}$, enabling reductive quenching from a variety of sacrificial electron donors (SEDs) $[35,36]$. With $\mathrm{E}\left(2 / \mathbf{2}^{-}\right) \approx-1 \mathrm{~V}_{\mathrm{SCE}}$, electron transfer from $\mathbf{2}$ to $\mathbf{1}$ is thermodynamically allowed in solution [37]. Besides, SED oxidation from the photoexcited CRC can also proceed to directly drive $\mathrm{CO}_{2}$ reduction with $\mathrm{E}\left(\mathbf{1}^{*} / \mathbf{1}^{-}\right)=1.26 \mathrm{~V}_{\mathrm{SCE}}[36,38]$. The synthesized MOFs, UiO-66(Zr) (66) and amine-modified $\mathrm{UiO}-66-\mathrm{NH}_{2}(\mathrm{Zr})\left(66-\mathrm{NH}_{2}\right)$, illustrated powder $\mathrm{X}$-ray diffraction (PXRD) reflexes in close agreement with simulated patterns from single crystal structures. This was also the case for zirconium oxide monoclinic nanoparticles $\left(\mathrm{ZrO}_{2}\right)$, highlighting crystallinity for all host systems (Figure 2a). $\mathrm{N}_{2}$ gas adsorption experiments revealed UiO's characteristic permanent porosity, giving Brunauer-Emmett-Teller (BET) areas of $960 \pm 4\left(\mathbf{6 6}-\mathbf{N H}_{2}\right), 965 \pm 3(\mathbf{6 6}), 12 \pm 1\left(\mathrm{ZrO}_{2}\right) \mathrm{m}^{2} \mathrm{~g}^{-1}$ (Figure S2). This striking discrepancy highlights the MOFs' porosity compared to an inorganic bulk material. Particle imaging occurred with scanning electron microscopy (SEM), showing uniform topology and morphology within each sample (Figure $2 b$ and Figures S3-S5). Importantly, analyzing particle sizes with histograms from SEM images gave average diameters of $55.2 \pm 9.1\left(\mathbf{6 6}-\mathbf{N H}_{2}\right)$, $48.6 \pm 7.0(66)$, and $48.8 \pm 6.2 \mathrm{~nm}\left(\mathrm{ZrO}_{2}\right)$ (Figure $\left.2 \mathrm{c}\right)$. Such closely matching values enable studying intrinsic dye-sensitized host effects unbiased by size-induced discrepancies. The latter has been shown to have significant implications in heterogeneous colloidal catalysis [39], including MOF-based reactions [13,39], with smaller particles favoring reactant transport, increasing accessible active sites, and providing larger surface-to-volume ratio [39]. Further, particles in the $\sim 50 \mathrm{~nm}$ size range are ideal as agglomeration was found to typically occur for pristine MOFs with $<50 \mathrm{~nm}[39,40]$.

66- $\mathbf{N H}_{2}$ was isolated as a light-yellow powder, 66 and $\mathrm{ZrO}_{2}$ as white powders, and their corresponding solid-state UV-Vis spectra showed no light absorption at wavelengths above $440 \mathrm{~nm}$ in all cases (Figure 3a). Applying the Tauc formula for pristine hosts yielded direct optical bandgaps of $2.86\left(66-\mathrm{NH}_{2}\right), 3.78(66)$, and $5.19 \mathrm{eV}\left(\mathrm{ZrO}_{2}\right)$, in-line with previously reported values, and suggesting exclusive dye excitation upon irradiation at higher wavelengths after dye sensitization (Figure S6) [21,41-43]. 

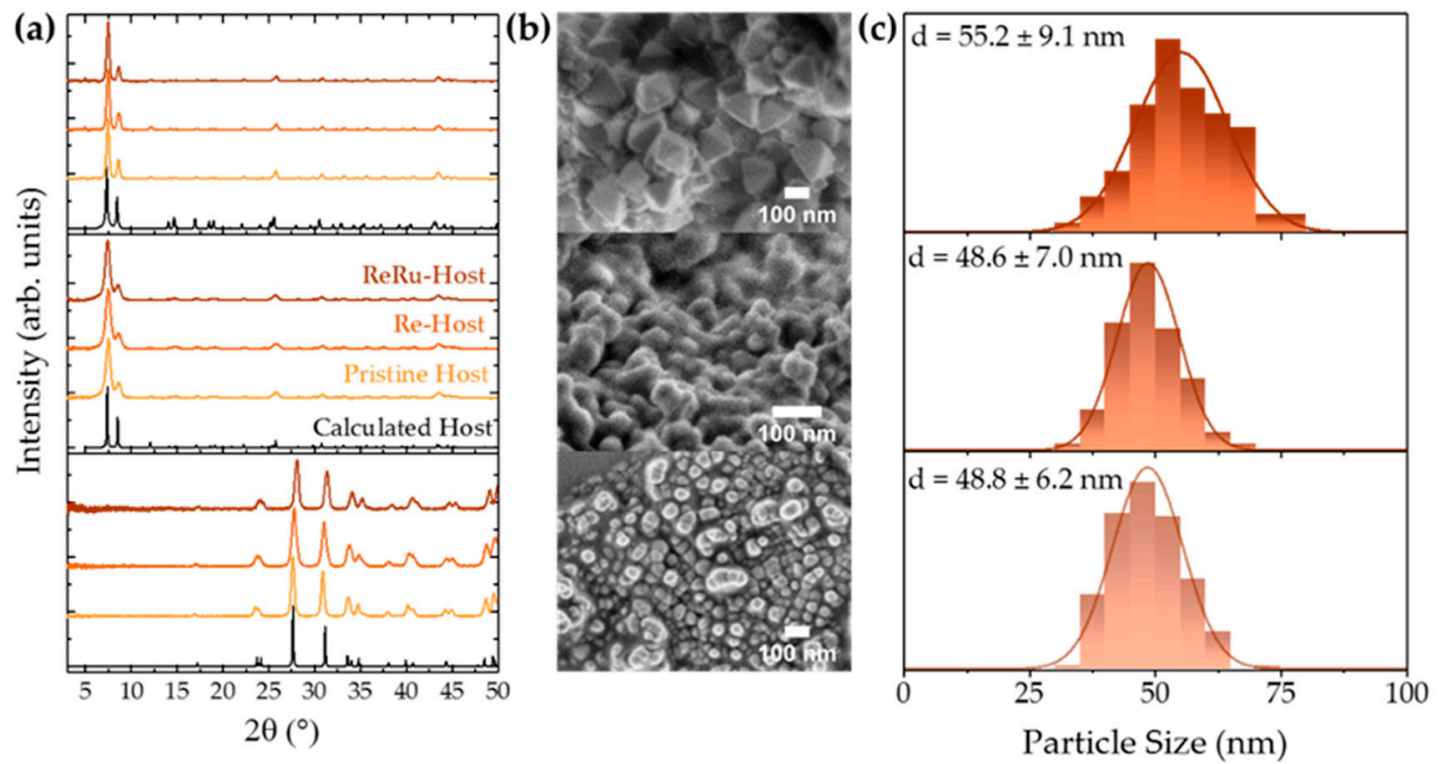

Figure 2. Characterization of 66- $\mathrm{NH}_{2}$-based (top), 66-based (middle), and $\mathrm{ZrO}_{2}$-based (bottom) assemblies. (a) Powder X-ray diffraction (PXRD) data with calculated reflexes (black) from single crystal data for each material, respectively. ReRu-Host samples are $\mathrm{R}=0.5$. (b) Representative SEM images for each pristine host. (c) Particle size distributions calculated from SEM images for unmodified host materials. Obtained from Figures $2 \mathrm{~b}$ and S3-S5.
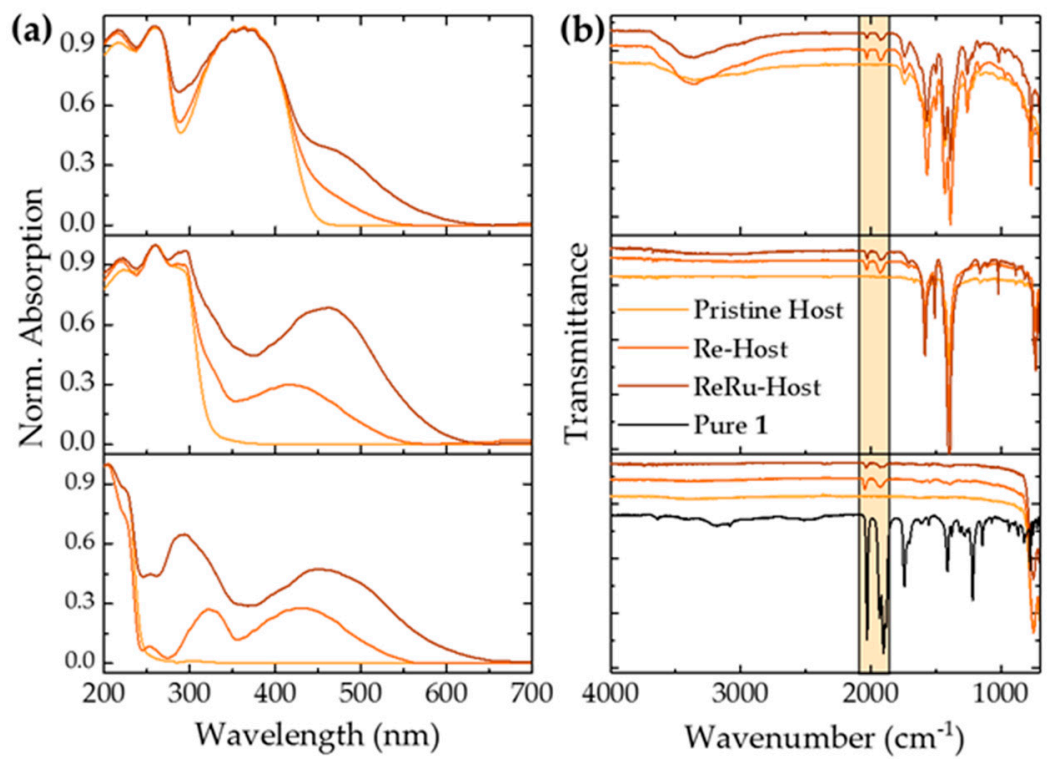

Figure 3. Solid-state UV-Vis and IR data for 66- $\mathrm{NH}_{2}$-based (top), 66-based (middle), and $\mathrm{ZrO}_{2}$-based (bottom) assemblies. (a) Normalized solid-state absorption spectra. (b) ATR-IR spectra, including pure catalyst 1 (black), and highlighting the $\operatorname{Re}(\mathrm{CO})_{3}$ band region between 1850 and $2100 \mathrm{~cm}^{-1}$. ReRu-host samples are $\mathrm{R}=0.5$.

\subsection{Host-Guest Photosystem Assembly}

Following the pristine host characterization, we sensitized the materials with photocatalyst $\mathbf{1}$ and dye 2 . This was achieved by soaking from a corresponding MeCN solution. The respective pristine host (10.0 $\mathrm{mg}$ in all cases) was immersed in a solution of $\mathbf{1}$ (and $\mathbf{2}$ ) in $\mathrm{MeCN}$ (quantities in Table S1) for $24 \mathrm{~h}$, then washed with pure MeCN and dried. Molecular species are expected to load specifically at the surface for all materials, as the MOF pore sizes, channels, and windows $(8.0 \AA)$ are substantially smaller than both molecular diameters (1: $12.0 \AA$; $2: 14.5 \AA$ ) [10]. Surface anchoring was monitored via supernatant UV-Vis 
spectroscopy, showing an absorption decay over time for all hosts, with stable values reached after $24 \mathrm{~h}$ (Figure S7). While $\mathbf{6 6}-\mathbf{N H}_{\mathbf{2}}$ and $\mathbf{6 6}$ provided comparable spectra, $\mathrm{ZrO}_{2}$ samples illustrated a smaller absorption decrease, suggesting a lower loading per mass of host. Further, measuring the washing solution after $8 \mathrm{~h}$ revealed no absorption in all cases, indicating no leaching and stable complex anchoring to the host surfaces (Figure S7).

Average maximum molecular surface loadings of $\sim 58, \sim 58$, and $\sim 32 \mathrm{nmol} \mathrm{mg}^{-1}$ were

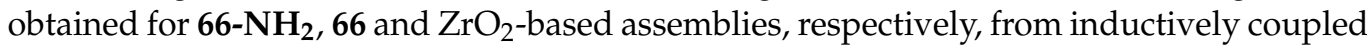
plasma mass spectrometry (ICP-MS) measurements for Ru and Re content (see SM). The lower loading for $\mathrm{ZrO}_{2}$-based assembly is in-line with the reduced absorption decay in the sensitizing solution compared to MOFs (Figure S7) and is rationalized by the higher crystal density of monoclinic zirconium oxide compared to porous UiO samples. Calculating surface areas and maximum coverages from SEM particle sizes (Figure 2b,c) with DFToptimized 1 and 2 gave values close to experimental ICP-MS results (SM, pages S4-S5), supporting that maximum surface coverage is attained by immobilization from solution. Exact metal contents further allowed molecular loading and photosensitizer to catalyst ratio calculations (R, Equation (1), Tables S1-S4). For each host in turn, assemblies with an $R$ value of 0.5 and 2.1 were synthesized (Tables S1-S4), i.e., a sample with double the molar catalyst quantity compared to the dye, and vice versa.

$$
\mathrm{R}=\mathrm{n}(\mathbf{2}) / \mathrm{n}(\mathbf{1})=\mathrm{n}(\text { Ru per mg host }) / \mathrm{n}(\text { Re per mg host })
$$

1-loaded, as well as 1- and 2-loaded assemblies, denoted as Re-Host and ReRu-host, respectively, were analyzed by PXRD, dynamic light scattering (DLS), attenuated total reflectance infrared (ATR-IR) spectroscopy, and solid-state UV-Vis spectroscopy to further assess the impact of molecular anchoring.

PXRD data of the functionalized hosts $(R=0.5)$ showed matching reflex positions as pristine hosts, suggesting retained sample crystallinity after the anchoring process (Figure 2a). Importantly, DLS distributions revealed comparable hydrodynamic diameters

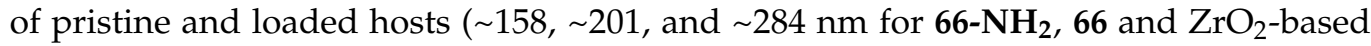
samples), highlighting that MOFs and nanoparticles do not agglomerate in MeCN solution and during molecular complex immobilization (Figure S8). The received hydrodynamic diameters are larger than actual particle diameters determined by SEM (Figure $2 b, c$ ) due to the hydration shell additionally detected in DLS measurements.

Solid-state UV-Vis spectroscopy of complex-containing samples displayed additional bands between 250 and $600 \mathrm{~nm}$ not present in pristine host spectra, matching 1 and 2 (Figure 3a). Further, ATR-IR spectra for all 1-loaded assemblies showed additional bands at 1917 and $2025 \mathrm{~cm}^{-1}$, which are characteristic of the $\operatorname{Re}(C O)_{3}$ moiety (Figure $3 b$ ). These support retained molecular catalyst integrity upon anchoring [11,44].

Finally, $\mathrm{N}_{2}$ gas adsorption experiments were conducted to evaluate the porosity of

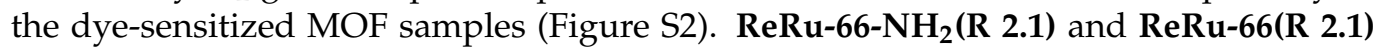
demonstrated a significant reduction in uptake in respect to their pristine counterparts, however, with a non-zero BET area of $338 \pm 1$ and $360 \pm 1 \mathrm{~m}^{2} \mathrm{~g}^{-1}$, respectively. This is in-line with previous studies, which showed that surface-anchored molecules of this size partially block outer MOF pores [10]. As for $\mathrm{ZrO}_{2}, \mathbf{R e R u}-\mathrm{ZrO}_{2}$ (R 2.1) illustrated negligible nitrogen adsorption.

\subsection{Photocatalytic Experiments}

The assemblies' light driven catalytic activity was studied to investigate host material and dye sensitization effects. Standard colloidal heterogeneous conditions were host-guest samples $(\sim 1 \mathrm{mg})$ in $\mathrm{MeCN}(4 \mathrm{~mL})$ and 1,3-dimethyl-2-phenyl-2,3-dihydro-1H-benzo[d]imidazole (BIH, $340 \mathrm{mg}, 1.5 \mathrm{mmol}$ ) or triethanolamine (TEOA, $0.2 \mathrm{~mL}, 1.5 \mathrm{mmol}$ ) as the SED. Such a significant excess of SED-to-photocatalyst (molar ratio $>25,000$ ) was chosen to ensure that the electron supply is not limiting.

$\mathrm{BIH}$ has been shown to give increased catalytic activity and stability compared to TEOA in homogeneous and heterogeneous photosystems $[11,38,45]$. The resulting sus- 
pension was first saturated with $\mathrm{CO}_{2}\left(\left[\mathrm{CO}_{2}\right] \approx 0.28 \mathrm{~mol} \mathrm{~L}^{-1}\right.$ for $\left.\mathrm{MeCN}\right)$ [46], and then vigorously stirred under irradiation at $450 \mathrm{~nm}$ (Blue LED LXZ1 PR01 at 5.1 W). The potential evolution of $\mathrm{H}_{2}$ and $\mathrm{CO}$ was analyzed via micro gas chromatography (GC) via reaction headspace sampling.

As a benchmark, homogeneous samples with pure catalyst, as well as dye and catalyst (ratio 2.0), were examined with both SEDs. For TEOA-based experiments, a solution of $0.5 \mu \mathrm{mol}$ pure 1 showed selective $\mathrm{CO}$ formation under irradiation that plateaued after 15 min reaching $11.2 \pm 0.3$ TONs per Re catalyst (Table S5, TON calculation in SM). Additionally, $0.5 \mu \mathrm{mol} 1$ with $1.0 \mu \mathrm{mol}$ of 2 resulted in a longer activity of $1.5 \mathrm{~h}$ before deactivation, while affording similar TONs as the PS-free experiments (Table S5). A comparable trend with higher absolute performances was observed with BIH as the SED, with $0.5 \mu \mathrm{mol}$ pure 1 reaching TONs of $173 \pm 7$ over $3 \mathrm{~h}$, and $0.5 \mu \mathrm{mol} 1$ with $1.0 \mu \mathrm{mol} 2$ yielding $182 \pm 15$ over $10 \mathrm{~h}$. Next, 1-loaded colloids were investigated. All three host materials showed limited activity with TONs below 5 and 100 for TEAO and BIH, respectively (Table S5). Subsequently, ReRu-host hybrid systems were examined (Figure 4a,b, Table S5). In all cases, the detected activity increased from $\mathrm{ReRu}-\mathrm{ZrO}_{2}$, to ReRu-66, and finally to ReRu-66- $\mathrm{NH}_{2}$ samples. When using $\mathrm{BIH}$ all host-guest systems reached significantly higher TONs than under homogeneous conditions whereas TEOA afforded similar or lower activities. Additionally, higher TONs compared to $\mathrm{R}=0.5$ samples were obtained with $\mathrm{R}=2.1$ with the highest activity $(\mathrm{TON}=450 \pm 15 ; \mathrm{BIH})$ reached for $\mathbf{R e R u}-\mathbf{6 6}-\mathbf{N H}_{\mathbf{2}}(\mathbf{R}=\mathbf{2 . 1})$.

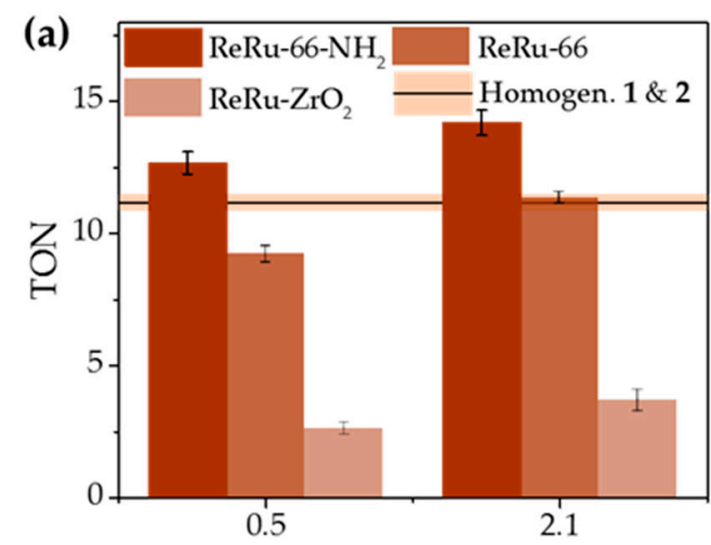

SED: TEOA $\quad \mathrm{R}$

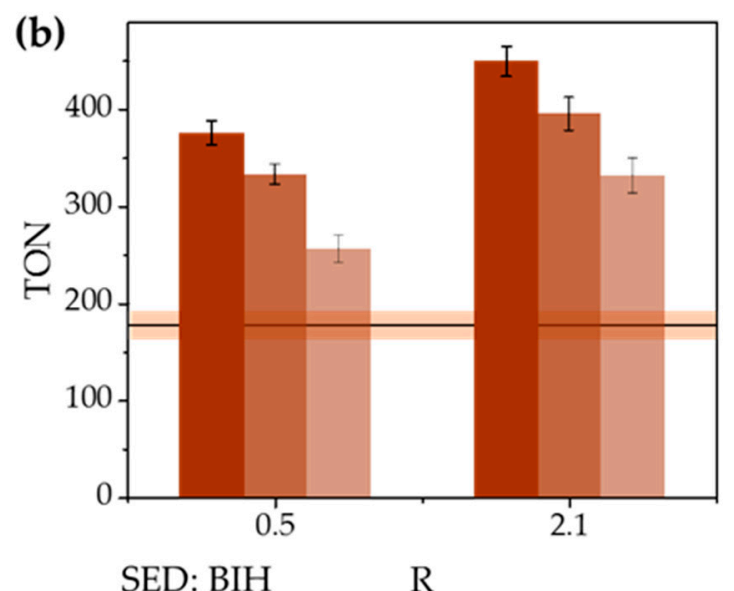

SED: BIH

Figure 4. Photocatalytic $\mathrm{CO}_{2}$ reduction to $\mathrm{CO}$ with various host-guest assemblies with differing dye-to-catalyst ratios $\mathrm{R}$ and either TEOA or BIH as the electron source. Standard conditions: MeCN, $1.5 \mathrm{mmol}$ SED, room temperature, $2.5 \mathrm{mg}$ sample, irradiation at $450 \mathrm{~nm}$. Homogeneous reference TON with pure $\mathbf{2}$ and $\mathbf{1}$ depicted as a horizontal black line with the respective error margins. (a) Experiments with TEOA, final TON attained after $5 \mathrm{~h}$. (b) Experiments with BIH, final TON attained after $10 \mathrm{~h}$.

Control experiments performed without irradiation or a SED yielded no detectable product formation under homogeneous conditions as well as colloidal photocatalysis (Table S5). Furthermore, $\mathrm{CO}_{2}$ was confirmed as the sole source of $\mathrm{CO}$ as ${ }^{13} \mathrm{C}$-labelled $\mathrm{CO}_{2}$ produced only ${ }^{13} \mathrm{CO}$ (Figure S9). Both experiments highlight the central role of each photosystem constituent in selective $\mathrm{CO}_{2}$ photoreduction.

The effectiveness of incident photon conversion to $\mathrm{CO}$ was determined with apparent quantum efficiency (AQE, Equation (2)) measurements under the best-performing conditions (BIH and $\mathrm{R}=2.1$ ) with details on formulas and measurements provided in the SM (Figure S10, Tables S6 and S7). AQEs of $2.2 \pm 0.2 \%\left(\mathbf{R e R u}-\mathbf{Z r O}_{\mathbf{2}}(\mathbf{R} 2.1)\right), 6.1 \pm 0.2 \%$ 
( $\mathbf{R e R u - 6 6 ( R ~ 2 . 1 ) ) , ~ a n d ~} 8.0 \pm 0.2 \%\left(\mathbf{R e R u}-66-\mathbf{N H}_{\mathbf{2}}\right.$ (R 2.1)) were obtained after the first $3.5 \mathrm{~h}$ of irradiation before decreasing reaction rates were observed, followed by deactivation.

AQE $(\%)=($ Moles of CO generated per unit of time/Number of incident photons per unit of time) $\cdot($ Number of required electrons) $\cdot 100 \%$

\section{Discussion}

The obtained homogeneous photocatalysis data matches previous studies with pure $\mathbf{1}$ showing modest activity and fast deactivation with TEOA, illustrating its instability under photocatalytic conditions [47]. Upon adding 2, the apparent CO evolution rate decreases, while not yielding effective electron transfers to the catalyst, apparent from unchanged TONs. This is ascribed to a too large mean distance between the photosystem components, as shown previously where higher dye concentrations or multinuclear complexes were required [4]. BIH was the more effective electron source as it quenches the excited state ${ }^{3} 2^{*}$ more efficiently and detrimental TEOA radicals limit molecular dye/catalyst stability $[11,45,47]$.

Comparing homogeneous results with 1 to heterogeneous 1-loaded colloids reveals a drop in performance for the latter independent of the SED. Similar performance decreases have been previously observed upon immobilizing $f a c-\left[\operatorname{ReCl}(\mathrm{CO})_{3}(\right.$ bpy) $]$-derivatives on $\mathrm{SiO}_{2}$ or $\mathrm{TiO}_{2}$ for photocatalysis and were assigned to reaction environment change and mass transport limitations $[29,48]$. This motivates dye-sensitization to drive efficient electron transfers to the catalyst units.

Upon providing surface proximity for $\mathbf{1}$ and 2, exergonic electron transfers from the photosensitizer to the catalyst can occur (relying on statistical molecular distribution), allowing rapid $\mathrm{CO}_{2}$ reduction and improved performance $[10,34]$. This working principle highlights the advantages of using dye-sensitized materials, as pure host-photocatalyst assemblies result in activity decreases. For all ReRu-host systems, an increased dye-to-catalyst ratio $\mathrm{R}$ yielded higher TONs as excess dye increases the probability of each $\mathrm{CO}_{2}$ reduction catalyst being in proximity to a photosensitizer [11]. Distinct differences were recorded between the three anchoring materials, with the performance increasing from $\mathrm{ReRu}-\mathrm{ZrO}_{2}$ (TON $\sim 331, \mathrm{R}=2.1, \mathrm{BIH})$, to ReRu-66 ( 395), to ReRu-66- $\mathrm{NH}_{2}(\sim 450)$ (Figure 4a,b). As all pristine host materials are photosilent at the irradiation wavelength of $450 \mathrm{~nm}$, exhibit similar particle size, and bear similar dye-to-catalyst ratios, this activity trend does not stem from a discrepancy between direct host light absorption (Figures 2c, 3a, 4a,b and S6).

To gain more insights into the difference in the catalytic performance, we examined the reduction and oxidation potentials of the ground and excited molecule states, as well as the Zr-based materials' conduction band energy levels. Reductive quenching, i.e., photoreduction of the PS from the SED followed by electron transfer to the CRC, is the main electron pathway in DSP systems with non-conducting hosts. As the scaffolds' conduction band (CB) edges were previously evaluated at $-3.3 \mathrm{eV}\left(\mathbf{6 6}-\mathbf{N H}_{2},-0.9 \mathrm{~V}_{\mathrm{SCE}}\right)$ [49], $-3.1 \mathrm{eV}$ $\left(66,-1.1 \mathrm{~V}_{\mathrm{SCE}}\right)$ [50], and $-2.1 \mathrm{eV}\left(\mathrm{ZrO}_{2},-2.1 \mathrm{~V}_{\mathrm{SCE}}\right)$ [51], the triplet state ${ }^{3} \mathbf{2}^{*}(-3.1 \mathrm{eV}$, $\left.-1.1 \mathrm{~V}_{\mathrm{SCE}}\right)$ is potentially able to inject electrons into the $\mathrm{CB}$ of $\mathbf{6 6}-\mathbf{N H}_{\mathbf{2}}$ through oxidative quenching, followed by regeneration from the SED. This could enable the MOF to act as a solid-state electron mediator, allowing electron hopping to distant catalyst units as $\mathrm{E}\left(\mathbf{1} / \mathbf{1}^{-}\right)=-3.3 \mathrm{eV}\left(-0.9 \mathrm{~V}_{\mathrm{SCE}}\right.$, Figure $\left.5 \mathrm{a}, \mathrm{c}\right)$. Electron hopping in MOFs is a topic of ongoing interest featuring reports of tailor-made MOFs with intrinsic conduction mechanisms and photoinduced electron injection by a $\mathrm{Ru}$ dye into a UiO material [52-54]. Although less thermodynamically favored, a similar electron cascade should also be possible with 66based DSM especially as Ru dyes have been reported to perform electron injection from

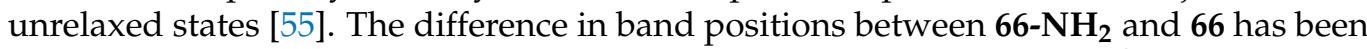
assigned to the amine-functionalized linkers, effecting a change of the $\mathrm{sp}^{2}$ bonding in the aromatic carbon ring [56]. In contrast, oxidative quenching is prevented for $\mathrm{ZrO}_{2}$-based DSP due to the high CB energy value (Figure 5a). This implies that the reductive quenching 
cascade is the sole viable electron cascade for catalysis, potentially limiting the final activity of the system in comparison to MOF-based systems [23].

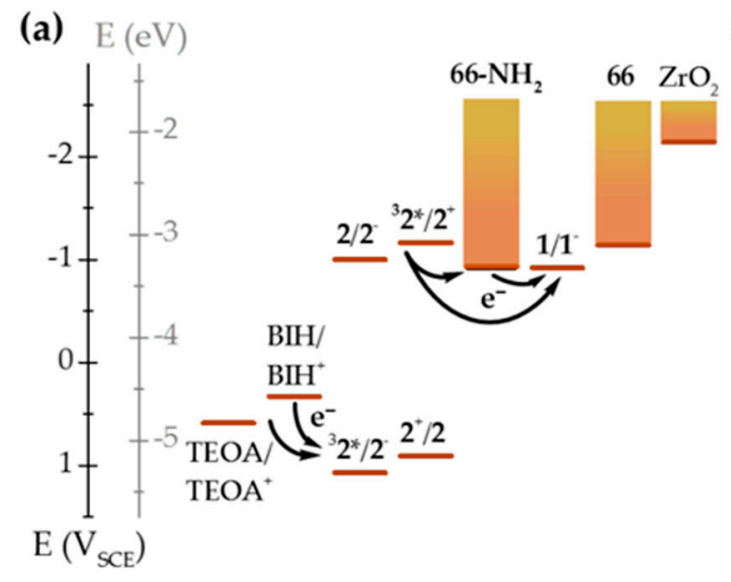

(c)

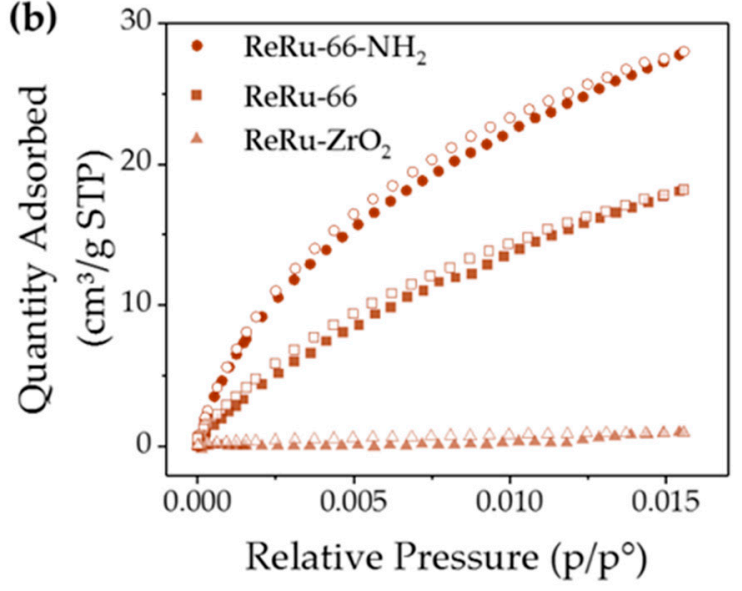

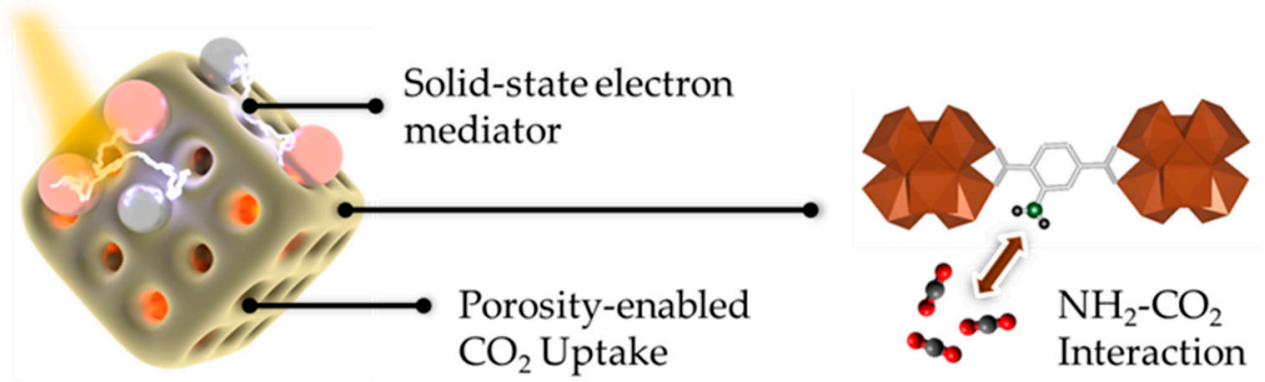

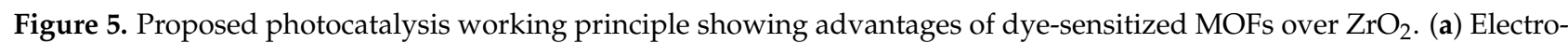
chemical potential representation of TEOA, BIH, the dye 2 , and the catalyst $\mathbf{1}$ to produce an efficient directional electron

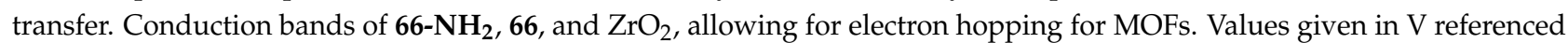

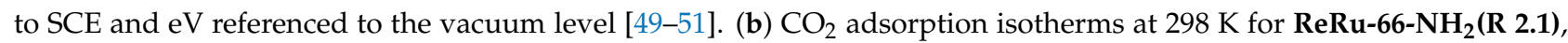
ReRu-66(R 2.1), and $\mathbf{R e R u - Z Z _ { 2 }}$ (R 2.1). (c) Schematic representation of dye- and catalyst-sensitized 66- $\mathbf{N H}_{2}$ under photocatalytic conditions, yielding increased performance due to electron hopping, intrinsic porosity-based $\mathrm{CO}_{2}$ uptake, and interactions between polar linker $\mathrm{NH}_{2}$ groups and $\mathrm{CO}_{2}$.

As photocatalysis proceeds in colloidal solution, the local $\mathrm{CO}_{2}$ concentration available for catalyst centers could impact the final activity. Despite maximum molecular loading on the scaffolds' surfaces, MOFs still provide a certain permanent porosity (Figure S2). To determine implications for photocatalysis, $\mathrm{CO}_{2}$ gas adsorption experiments at room temperature were conducted with the three hosts (Figure $5 b$ ). As a non-porous crystalline solid, $\mathrm{ReRu}-\mathrm{ZrO}_{2}$ is not able to adsorb carbon dioxide within its structure and is therefore reliant on the diffusion of available $\mathrm{CO}_{2}$ in solution. This differs for MOFs, as their intrinsic porosity could allow gas uptake when the reaction solution is saturated with $\mathrm{CO}_{2}$ prior to irradiation. Noteworthy is that $\mathbf{R e} \mathbf{R u}-\mathbf{6 6}-\mathbf{N H}_{\mathbf{2}}(\mathbf{R} \mathbf{2 . 1})$ shows markedly higher uptake than ReRu-66(R 2.1), despite comparable $\mathrm{N}_{2}$ adsorption isotherms (Figures $5 \mathrm{~b}$ and S2). This has been previously observed and attributed to interactions/reactions between the polar linkers' amine groups and carbon dioxide (Figure 5c) [57,58].

Thus, 66- $\mathbf{N H}_{2}$ provides an increased local $\mathrm{CO}_{2}$ concentration available during the course of photocatalysis, thereby reducing diffusion limitations, as well as potentially activating $\mathrm{CO}_{2}$ [59]. This is potentially shown by increased turnover frequencies (TOFs) from $\mathrm{ZrO}_{2}$-based, to 66-based, to 66- $\mathrm{NH}_{2}$-based assemblies (Figure S10). Such reactant-hostguest synergies are a unique benefit of DSM over conventional DSP (Figure $5 \mathrm{c}$ ), yielding higher performances. This increase in efficiency is also apparent from obtained AQEs which improve from $2.2 \pm 0.2 \%$ for $\mathbf{R e R u}-\mathbf{Z r O}_{\mathbf{2}}(\mathbf{R} \mathbf{2 . 1})$ to $8.0 \pm 0.2 \%$ for $\mathbf{R e R u}-66-\mathbf{N H}_{\mathbf{2}}(\mathbf{R}$ 2.1) under ideal conditions (Tables S6 and S7), allowing incident photons to be converted more 
effectively to $\mathrm{CO}$. The obtained performance and TONs for ReRu-66- $\mathrm{NH}_{2}$ are comparable to state-of-the-art dye-sensitized semiconductors with Re-based molecular catalysts. For instance, dye-sensitized $\mathrm{TiO}_{2}$ nanoparticles with $\mathrm{ReCl}(\mathrm{CO})_{3}$ (bpy)-derivatives reached maximum TONs between 165 and 570 in DMF with $\mathrm{BIH}$, depending on irradiation conditions [26,27]. This system showed an AQE of $2.1 \%$ at $436 \mathrm{~nm}$ [27], and a recent report with organosilica nanotubes and anchored 1 and 2 yielded AQEs between $0.4 \%$ and $15.1 \%$ at $450 \mathrm{~nm}$, depending on reaction conditions [60]. Accordingly, our results are well within this benchmark range for DSP with colloidal host-guest systems.

\section{Conclusions}

Herein we designed a model study to compare dye-sensitized metal oxides to metalorganic frameworks for colloidal photocatalytic $\mathrm{CO}_{2}$ reduction. Thus, monoclinic $\mathrm{ZrO}_{2}$ was evaluated against $\mathrm{Zr}$-based MOFs $\mathbf{6 6}$ and $\mathbf{6 6}-\mathbf{N H}_{2}$, all with surface co-immobilized molecular carbon dioxide reduction photocatalyst $f a c-\operatorname{ReBr}(\mathrm{CO})_{3}\left(4,4^{\prime}\right.$-dcbpy) and photosensitizer $\mathrm{Ru}(\mathrm{bpy})_{2}\left(5,5^{\prime}\right.$-dcbpy $) \mathrm{Cl}_{2}$. Photocatalytic $\mathrm{CO}_{2}$-to- $\mathrm{CO}$ performance increased from $\mathrm{ZrO}_{2}$, to UiO-66, and $\mathrm{UiO}-66-\mathrm{NH}_{2}$, respectively. While the former provides fixed proximity for the molecular photosystem constituents, the studied MOF scaffolds offer additional synergistic host properties. Particularly $\mathbf{6 6}-\mathbf{N H}_{\mathbf{2}}$ could enable host-mediated electron hopping, paired with uniquely increased $\mathrm{CO}_{2}$ adsorption capacity from its permanent porosity and $\mathrm{NH}_{2}-\mathrm{CO}_{2}$ interaction. These combined phenomena enable an AQE of up to $8 \%$ for the studied DSM.

Overall, these findings highlight how DSM can combine multiple functionalities to drive photocatalysis and provide tunable material composites. Our results competitively position dye-sensitized MOFs as a hybrid material for efficient solar fuel production, which could be further exploited with alternative optimized components toward higher performance in the future.

Supplementary Materials: The following are available online at https:/ / www.mdpi.com/article/10.3 390/en14144260/s1: Detailed overview on all synthetic procedures, the analytical instrumentation and characterization methods, supporting calculations, as well as additional measurement data.

Author Contributions: Conceptualization, P.M.S. and J.W.; methodology, P.M.S.; formal analysis, P.M.S.; investigation, P.M.S.; data curation, P.M.S.; writing-original draft preparation, P.M.S. and J.W.; writing-review and editing, P.M.S. and J.W.; visualization, P.M.S.; supervision, J.W.; funding acquisition, J.W. All authors have read and agreed to the published version of the manuscript.

Funding: This research was funded by the German Research Foundation (DFG), research grant MOFMOX (FI 502/43-1) and P.M.S. was supported by the Chemical Industry Fonds with a PhD stipend.

Institutional Review Board Statement: Not applicable.

Informed Consent Statement: Not applicable.

Data Availability Statement: The data presented in this study are available in the article and Supporting Information. For more specific questions a request can be sent to the corresponding author.

Acknowledgments: We thank Katia Rodewald for SEM, as well as Alexander Urstöger and Michael Schuster for ICP-MS, and Johanna Haimerl for helpful discussions. Ladawan Pukdeejorhor's and Johanna Haimerl's help in proof reading is greatly appreciated.

Conflicts of Interest: The authors declare no conflict of interest. The funders had no role in the design of the study; in the collection, analyses, or interpretation of data; in the writing of the manuscript, or in the decision to publish the results.

\section{References}

1. IEA. World Energy Outlook 2019; IEA: Paris, France, 2019.

2. Kumaravel, V.; Bartlett, J.; Pillai, S.C. Photoelectrochemical Conversion of Carbon Dioxide $\left(\mathrm{CO}_{2}\right)$ into Fuels and Value-Added Products. ACS Energy Lett. 2020, 5, 486-519. [CrossRef]

3. Dalle, K.E.; Warnan, J.; Leung, J.J.; Reuillard, B.; Karmel, I.S.; Reisner, E. Electro- and Solar-Driven Fuel Synthesis with First Row Transition Metal Complexes. Chem. Rev. 2019, 119, 2752-2875. [CrossRef] 
4. Sahara, G.; Ishitani, O. Efficient Photocatalysts for $\mathrm{CO}_{2}$ Reduction. Inorg. Chem. 2015, 54, 5096-5104. [CrossRef]

5. Zhang, B.; Sun, L. Artificial Photosynthesis: Opportunities and Challenges of Molecular Catalysts. Chem. Soc. Rev. 2019, 48, 2216-2264. [CrossRef]

6. Willkomm, J.; Orchard, K.L.; Reynal, A.; Pastor, E.; Durrant, J.R.; Reisner, E. Dye-sensitised semiconductors modified with molecular catalysts for light-driven $\mathrm{H}_{2}$ production. Chem. Soc. Rev. 2016, 45, 9-23. [CrossRef]

7. Hagfeldt, A.; Boschloo, G.; Sun, L.; Kloo, L.; Pettersson, H. Dye-sensitized solar cells. Chem. Rev. 2010, 110, 6595-6663. [CrossRef]

8. Fabian, D.M.; Hu, S.; Singh, N.; Houle, F.A.; Hisatomi, T.; Domen, K.; Osterloh, F.E.; Ardo, S. Particle suspension reactors and materials for solar-driven water splitting. Energy Environ. Sci. 2015, 8, 2825-2850. [CrossRef]

9. Wang, Q.; Domen, K. Particulate Photocatalysts for Light-Driven Water Splitting: Mechanisms, Challenges, and Design Strategies. Chem. Rev. 2020, 120, 919-985. [CrossRef]

10. Stanley, P.M.; Haimerl, J.; Thomas, C.; Urstoeger, A.; Schuster, M.; Shustova, N.B.; Casini, A.; Rieger, B.; Warnan, J.; Fischer, R.A. Host-Guest Interactions in Metal-Organic Framework Isoreticular Series for Molecular Photocatalytic $\mathrm{CO}_{2}$ Reduction. Angezw. Chem. Int. Ed. 2021. [CrossRef]

11. Stanley, P.M.; Thomas, C.; Thyrhaug, E.; Urstoeger, A.; Schuster, M.; Hauer, J.; Rieger, B.; Warnan, J.; Fischer, R.A. Entrapped Molecular Photocatalyst and Photosensitizer in Metal-Organic Framework Nanoreactors for Enhanced Solar $\mathrm{CO}_{2}$ Reduction. ACS Catal. 2021, 11, 871-882. [CrossRef]

12. Wang, X.; Wisser, F.M.; Canivet, J.; Fontecave, M.; Mellot-Draznieks, C. Immobilization of a Full Photosystem in the Large-Pore MIL-101 Metal-Organic Framework for $\mathrm{CO}_{2}$ reduction. ChemSusChem 2018, 11, 3315-3322. [CrossRef]

13. Stanley, P.M.; Parkulab, M.; Rieger, B.; Warnan, J.; Fischer, R.A. Understanding entrapped molecular photosystem and metalorganic framework synergy for improved solar fuel production. Faraday Discuss. 2021. [CrossRef]

14. Furukawa, H.; Cordova, K.E.; O'Keeffe, M.; Yaghi, O.M. The chemistry and applications of metal-organic frameworks. Science 2013, 341, 1230444. [CrossRef]

15. Leith, G.A.; Martin, C.R.; Mayers, J.M.; Kittikhunnatham, P.; Larsen, R.W.; Shustova, N.B. Confinement-guided photophysics in MOFs, COFs, and cages. Chem. Soc. Rev. 2021. [CrossRef]

16. Hendon, C.H.; Tiana, D.; Walsh, A. Conductive metal-organic frameworks and networks: Fact or fantasy? Phys. Chem. Chem. Phys. 2012, 14, 13120-13132. [CrossRef]

17. Cavka, J.H.; Jakobsen, S.; Olsbye, U.; Guillou, N.; Lamberti, C.; Bordiga, S.; Lillerud, K.P. A new zirconium inorganic building brick forming metal organic frameworks with exceptional stability. J. Am. Chem. Soc. 2008, 130, 13850-13851. [CrossRef]

18. Winarta, J.; Shan, B.; Mcintyre, S.M.; Ye, L.; Wang, C.; Liu, J.; Mu, B. A Decade of UiO-66 Research: A Historic Review of Dynamic Structure, Synthesis Mechanisms, and Characterization Techniques of an Archetypal Metal-Organic Framework. Cryst. Growth Des. 2019, 20, 1347-1362. [CrossRef]

19. Chen, Y.-F.; Tan, L.-L.; Liu, J.-M.; Qin, S.; Xie, Z.-Q.; Huang, J.-F.; Xu, Y.-W.; Xiao, L.-M.; Su, C.-Y. Calix[4]arene based dye-sensitized Pt@UiO-66- $\mathrm{NH}_{2}$ metal-organic framework for efficient visible-light photocatalytic hydrogen production. Appl. Catal. B-Environ. 2017, 206, 426-433. [CrossRef]

20. He, J.; Wang, J.; Chen, Y.; Zhang, J.; Duan, D.; Wang, Y.; Yan, Z. A dye-sensitized Pt@UiO-66(Zr) metal-organic framework for visible-light photocatalytic hydrogen production. Chem. Commun. 2014, 50, 7063-7066. [CrossRef]

21. Hendrickx, K.; Vanpoucke, D.E.P.; Leus, K.; Lejaeghere, K.; van Yperen-De Deyne, A.; van Speybroeck, V.; Van Der Voort, P.; Hemelsoet, K. Understanding Intrinsic Light Absorption Properties of UiO-66 Frameworks: A Combined Theoretical and Experimental Study. Inorg. Chem. 2015, 54, 10701-10710. [CrossRef]

22. Chen, Q.; He, Q.; Lv, M.; Xu, Y.; Yang, H.; Liu, X.; Wei, F. Selective adsorption of cationic dyes by UiO-66-NH2. Appl. Surf. Sci. 2015, 327, 77-85. [CrossRef]

23. Gross, M.A.; Reynal, A.; Durrant, J.R.; Reisner, E. Versatile photocatalytic systems for $\mathrm{H}_{2}$ generation in water based on an efficient DuBois-type nickel catalyst. J. Am. Chem. Soc. 2014, 136, 356-366. [CrossRef]

24. Hawecker, J.; Lehn, J.-M.; Ziessel, R. Efficient Photochemical Reduction of $\mathrm{CO}_{2}$ to $\mathrm{CO}$ by Visible Light Irradiation of Systems Containing $\operatorname{Re}($ bipy $)(\mathrm{CO})_{3} \mathrm{X}$ or $\mathrm{Ru}(\text { bipy })_{3}{ }^{2+}-\mathrm{Co}^{2+}$ Combinations as Homogeneous Catalysts. J. Chem. Soc. Chem. Commun. 1983, 9, 536-538. [CrossRef]

25. Pfennig, B.W.; Chen, P.; Meyer, T.J. Photophysics and Photochemistry of Chromophore-Quencher Assemblies on Glass and Powdered Silica. Inorg. Chem. 1996, 35, 2898-2901. [CrossRef]

26. Ha, E.-G.; Chang, J.-A.; Byun, S.-M.; Pac, C.; Jang, D.-M.; Park, J.; Kang, S.O. High-turnover visible-light photoreduction of CO 2 by a $\operatorname{Re}(\mathrm{I})$ complex stabilized on dye-sensitized $\mathrm{TiO}_{2}$. Chem. Commun. 2014, 50, 4462-4464. [CrossRef]

27. Won, D.-I.; Lee, J.-S.; Ji, J.-M.; Jung, W.-J.; Son, H.-J.; Pac, C.; Kang, S.O. Highly Robust Hybrid Photocatalyst for Carbon Dioxide Reduction: Tuning and Optimization of Catalytic Activities of Dye/ $\mathrm{TiO}_{2} / \mathrm{Re}(\mathrm{I})$ Organic-Inorganic Ternary Systems. J. Am. Chem. Soc. 2015, 137, 13679-13690. [CrossRef]

28. Windle, C.D.; Pastor, E.; Reynal, A.; Whitwood, A.C.; Vaynzof, Y.; Durrant, J.R.; Perutz, R.N.; Reisner, E. Improving the photocatalytic reduction of $\mathrm{CO}_{2}$ to $\mathrm{CO}$ through immobilisation of a molecular Re catalyst on $\mathrm{TiO}_{2}$. Chem. Eur. J. 2015, 21, 3746-3754. [CrossRef]

29. Liu, C.; Dubois, K.D.; Louis, M.E.; Vorushilov, A.S.; Li, G. Photocatalytic $\mathrm{CO}_{2}$ Reduction and Surface Immobilization of a Tricarbonyl Re(I) Compound Modified with Amide Groups. ACS Catal. 2013, 3, 655-662. [CrossRef] 
30. Kouva, S.; Honkala, K.; Lefferts, L.; Kanervo, J. Review: Monoclinic zirconia, its surface sites and their interaction with carbon monoxide. Catal. Sci. Technol. 2015, 5, 3473-3490. [CrossRef]

31. Hou, C.-C.; Li, T.-T.; Cao, S.; Chen, Y.; Fu, W.-F. Incorporation of a $\left[\mathrm{Ru}(\mathrm{dcbpy})(\mathrm{bpy})_{2}\right]^{2+} \mathrm{Photosensitizer} \mathrm{and} \mathrm{a} \mathrm{Pt(dcbpy)Cl}_{2}$ Catalyst into Metal-Organic Frameworks for Photocatalytic Hydrogen Evolution from Aqueous Solution. J. Mater. Chem. A 2015, 3, 10386-10394. [CrossRef]

32. Sun, D.; Fu, Y.; Liu, W.; Ye, L.; Wang, D.; Yang, L.; Fu, X.; Li, Z. Studies on photocatalytic $\mathrm{CO}_{2}$ reduction over $\mathrm{NH}_{2}-\mathrm{UiO}-66(\mathrm{Zr})$ and its derivatives: Towards a better understanding of photocatalysis on metal-organic frameworks. Chem. Eur. J. 2013, 19, 14279-14285. [CrossRef]

33. Hou, L.; Wang, L.; Zhang, N.; Xie, Z.; Dong, D. Polymer brushes on metal-organic frameworks by UV-induced photopolymerization. Polym. Chem. 2016, 7, 5828-5834. [CrossRef]

34. Smieja, J.M.; Kubiak, C.P. Re(bipy-tBu)(CO) $)_{3}$ Cl-improved Catalytic Activity for Reduction of Carbon Dioxide: IRspectroelectrochemical and mechanistic studies. Inorg. Chem. 2010, 49, 9283-9289. [CrossRef]

35. Sun, H.; Hoffman, M.Z. Reductive Quenching of the Excited States of Ruthenium(II) Complexes Containing 2,2'-Bipyridine, 2,2'-Bipyrazine, and 2,2'-Bipyrimidine Ligands. J. Phys. Chem. 1994, 98, 11719-11726. [CrossRef]

36. Pellegrin, Y.; Odobel, F. Sacrificial Electron Donor Reagents for Solar Fuel Production. Cr. Chim. 2017, 20, 283-295. [CrossRef]

37. Gholamkhass, B.; Mametsuka, H.; Koike, K.; Tanabe, T.; Furue, M.; Ishitani, O. Architecture of supramolecular metal complexes for photocatalytic $\mathrm{CO}_{2}$ reduction: Ruthenium-rhenium bi- and tetranuclear complexes. Inorg. Chem. 2005, 44, 2326-2336. [CrossRef]

38. Tamaki, Y.; Ishitani, O. Supramolecular Photocatalysts for the Reduction of $\mathrm{CO}_{2}$. ACS Catal. 2017, 7, 3394-3409. [CrossRef]

39. Semrau, A.L.; Stanley, P.M.; Urstoeger, A.; Schuster, M.; Cokoja, M.; Fischer, R.A. Substantial Turnover Frequency Enhancement of MOF Catalysts by Crystallite Downsizing Combined with Surface Anchoring. ACS Catal. 2020, 10, 3203-3211. [CrossRef]

40. Semrau, A.L.; Pujari, S.P.; Stanley, P.M.; Wannapaiboon, S.; Albada, B.; Zuilhof, H.; Fischer, R.A. Selective Positioning of Nanosized Metal-Organic Framework Particles at Patterned Substrate Surfaces. Chem. Mater. 2020, 32, 9954-9963. [CrossRef]

41. Tauc, J.; Grigorovici, R.; Vancu, A. Optical Properties and Electronic Structure of Amorphous Germanium. Phys. Stat. Sol. 1966, 15, 627-637. [CrossRef]

42. Timofeeva, M.N.; Panchenko, V.N.; Jun, J.W.; Hasan, Z.; Matrosova, M.M.; Jhung, S.H. Effects of linker substitution on catalytic properties of porous zirconium terephthalate UiO-66 in acetalization of benzaldehyde with methanol. Appl. Catal. A Gen. 2014, 471, 91-97. [CrossRef]

43. Horti, N.C.; Kamatagi, M.D.; Nataraj, S.K.; Wari, M.N.; Inamdar, S.R. Structural and optical properties of zirconium oxide $\left(\mathrm{ZrO}_{2}\right)$ nanoparticles: Effect of calcination temperature. Nano Ex. 2020, 1, 10022. [CrossRef]

44. Vlček, A. Ultrafast Excited-State Processes in Re(I) Carbonyl-Diimine Complexes: From Excitation to Photochemistry. In Photophysics of Organometallics; Lees, A.J., Castellano, F.N., Eds.; Springer: Berlin/Heidelberg, Germany, 2010; pp. 115-158, ISBN 9783642047282.

45. Tamaki, Y.; Koike, K.; Morimoto, T.; Ishitani, O. Substantial Improvement in the Efficiency and Durability of a Photocatalyst for Carbon Dioxide Reduction Using a Benzoimidazole Derivative as an Electron Donor. J. Catal. 2013, 304, 22-28. [CrossRef]

46. Fujita, E.; Szalda, D.J.; Creutz, C.; Sutin, N. Carbon dioxide activation: Thermodynamics of carbon dioxide binding and the involvement of two cobalt centers in the reduction of carbon dioxide by a cobalt(I) macrocycle. J. Am. Chem. Soc. 1988, 110, 4870-4871. [CrossRef]

47. Meister, S.; Reithmeier, R.O.; Tschurl, M.; Heiz, U.; Rieger, B. Unraveling Side Reactions in the Photocatalytic Reduction of $\mathrm{CO}_{2}$ : Evidence for Light-Induced Deactivation Processes in Homogeneous Photocatalysis. ChemCatChem 2015, 7, 690-697. [CrossRef]

48. Orchanian, N.M.; Hong, L.E.; Skrainka, J.A.; Esterhuizen, J.A.; Popov, D.A.; Marinescu, S.C. Surface-Immobilized Conjugated Polymers Incorporating Rhenium Bipyridine Motifs for Electrocatalytic and Photocatalytic $\mathrm{CO}_{2}$ Reduction. ACS Appl. Energy Mater. 2018, 2, 110-123. [CrossRef]

49. Zhang, H.; Li, J.; He, X.; Liu, B. Preparation of a g- $\mathrm{C}_{3} \mathrm{~N}_{4} / \mathrm{UiO}-66-\mathrm{NH}_{2} /$ CdS Photocatalyst with Enhanced Visible Light Photocatalytic Activity for Tetracycline Degradation. Nanomaterials 2020, 10, 1824. [CrossRef]

50. Stojković, M.; Pašti, I.A. Strain Engineering for Tuning the Photocatalytic Activity of Metal-Organic Frameworks-Theoretical Study of the UiO-66 Case. Catalysts 2021, 11, 264. [CrossRef]

51. Gritsenko, V.A.; Novikov, Y.N.; Perevalov, T.V.; Kruchinin, V.N.; Aliev, V.S.; Gerasimova, A.K.; Erenburg, S.B.; Trubina, S.V.; Kvashnina, K.O.; Prosvirin, I.P.; et al. Nanoscale Potential Fluctuations in Zirconium Oxide and the Flash Memory Based on Electron and Hole Localization. Adv. Electron. Mater. 2018, 4, 1700592. [CrossRef]

52. Neumann, T.; Liu, J.; Wächter, T.; Friederich, P.; Symalla, F.; Welle, A.; Mugnaini, V.; Meded, V.; Zharnikov, M.; Wöll, C.; et al. Superexchange Charge Transport in Loaded Metal Organic Frameworks. ACS Nano 2016, 10, 7085-7093. [CrossRef]

53. Hod, I.; Farha, O.K.; Hupp, J.T. Modulating the rate of charge transport in a metal-organic framework thin film using host:guest chemistry. Chem. Commun. 2016, 52, 1705-1708. [CrossRef]

54. Santiago-Portillo, A.; Baldoví, H.G.; Carbonell, E.; Navalón, S.; Álvaro, M.; García, H.; Ferrer, B. Ruthenium(II) Tris(2,2'-bipyridyl) Complex Incorporated in UiO-67 as Photoredox Catalyst. J. Phys. Chem. C 2018, 122, 29190-29199. [CrossRef]

55. Asbury, J.B.; Wang, Y.-Q.; Hao, E.; Ghosh, H.N.; Lian, T. Evidences of hot excited state electron injection from sensitizer molecules to $\mathrm{TiO}_{2}$ nanocrystalline thin films. Res. Chem. Intermed. 2001, 27, 393-406. [CrossRef]

56. Musho, T.D.; Yasin, A.S. Ab-initio Study of the Electron Mobility in a Functionalized UiO-66 Metal Organic Framework. J. Electron. Mater. 2018, 47, 3692-3700. [CrossRef] 
57. Huang, Q.; Ding, J.; Huang, X.; Wei, X.; Wang, W. Experimental and Computational Investigation of $\mathrm{CO}_{2}$ Capture on Mix-ligand Metal-organic Framework UiO-66. Energy Procedia 2017, 105, 4395-4401. [CrossRef]

58. Flaig, R.W.; Osborn Popp, T.M.; Fracaroli, A.M.; Kapustin, E.A.; Kalmutzki, M.J.; Altamimi, R.M.; Fathieh, F.; Reimer, J.A.; Yaghi, O.M. The Chemistry of $\mathrm{CO}_{2}$ Capture in an Amine-Functionalized Metal-Organic Framework under Dry and Humid Conditions. J. Am. Chem. Soc. 2017, 139, 12125-12128. [CrossRef]

59. Jakobsen, J.B.; Rønne, M.H.; Daasbjerg, K.; Skrydstrup, T. Are Amines the Holy Grail for Facilitating $\mathrm{CO}_{2}$ Reduction? Angew. Chem. Int. Ed. 2021, 60, 9174-9179. [CrossRef]

60. Waki, M.; Ikai, M.; Goto, Y.; Maegawa, Y.; Inagaki, S. Re(bpy) $(\mathrm{CO})_{3} \mathrm{Cl}$ Immobilized on Bipyridine Organosilica Nanotubes for Photocatalytic $\mathrm{CO}_{2}$ Reduction. Eur. J. Inorg. Chem. 2021, 4, 1259. [CrossRef] 